\title{
ANALISIS PENYAMBUNGAN FIBER OPTIK (FO) DENGAN METODE FUSI PADA JARINGAN TELEKOMUNIKASI DI KAMPUS UNIVERSITAS NEGERI SURABAYA KETINTANG
}

\author{
Mohammad Ahied ${ }^{1}$,Dzulkiflih ${ }^{2}$ \\ ${ }^{1}$ Jurusan Pendidikan IPA \\ Fakultas Ilmu Pendidikan \\ Universitas Trunojoyo Madura \\ e-mail: ahied@trunojoyo.ac.id \\ ${ }^{2}$ Jurusan Fisika Fakultas Matematika dan Ilmu Pengetahuan Alam Unesa \\ Kampus Ketintang Surabaya 60231,Telp.(031)-8289070 \\ e-mail: dzulkiflihaa@yahoo.com
}

\begin{abstract}
ABSTRAK
Telah dilakukan penelitian tentang penyambungan serat optik dengan metode fusi dengan tujuan untuk mengetahui hasil dari penyambungan serat optik, terutama ditinjau dari rugi-rugi penyambungan splicing loss, loss (redaman) dan redaman per $\mathrm{Km}$ (kilometer) dari sistem saluran serat optik jaringan telekomunikasi yang dipasang di Kampus Universitas Negeri Surabaya. Adapun metode yang dilakukan adalah metode eksperimen, dimana peneliti melakukan penyambungan serat optik dengan metode fusi kemudian mengukur splicing loss dan loss (redaman), dari data ini dapat dihitung redaman per Km(kilometer)nya. Dari semua penyambungan serat optik dengan metode fusi yang dilakukan menghasilkan splicing loss yang sama sebesar $0 \mathrm{~dB}$, dan menghasilkan redaman per $\mathrm{Km}$ (kilometer) yang nilainya bervariasi, yaitui $0 \mathrm{~dB}, 0.0350 \mathrm{~dB}$, $0.0384 \mathrm{~dB}, 0.0543 \mathrm{~dB}, 0.0701 \mathrm{~dB}, 0.1153 \mathrm{~dB}$, dan $0.1630 \mathrm{~dB}$. Besarnya splicing loss dan redaman per $\mathrm{Km}$ (kilometer) ini masih bisa digunakan karena masih memenuhi standar yaitu maksimum 0,2 dB sebagai acuan untuk splicing loss dan maksimum $0,3 \mathrm{~dB}$ sebagai acuan untuk redaman.
\end{abstract}

Key words : Serat optic, metode fusi, splicing loss, loss/redaman.

\section{ABSTRACT}

A research on the connection of the optical fiber with fusion method in order to determine the result of splicing optical fibers, especially in terms of losses splicing splicing loss, loss (attenuation) and attenuation per Km (kilometers) of the duct system of fiber-optic telecommunications network installed on the campus of the State University of Surabaya. The method is carried out is an experimental method, where researchers conduct splicing optical fiber with fusion method then measure splicing loss and loss (attenuation), this data can be calculated from the attenuation per Km (kilometers) it. Of all the splicing of optical fiber with fusion methods that do generate splicing loss is the same at $0 \mathrm{~dB}$, and generate attenuation per Km (kilometers) whose value varies, yaitui $0 \mathrm{~dB}, 0.0350 \mathrm{~dB}, 0.0384 \mathrm{~dB}, 0.0543 \mathrm{~dB}, 0.0701 \mathrm{~dB}, 0.1153 \mathrm{~dB}$, and $0.1630 \mathrm{~dB}$. The amount of splicing loss and attenuation per Km (kilometers) can still be used because they meet the standards that is a maximum of $0.2 \mathrm{~dB}$ as a reference for splicing and maximum loss of $0.3 \mathrm{~dB}$ as a reference for attenuation.

Keyword: fiber optic, loss.method fusion, splicing loss 


\section{PENDAHULUAN}

Penerapan teknologi jaringan baru sudah seharusnya diawali dengan evaluasi terhadap kondisi teknologi dan jaringan yang ada dan selanjutnya menentukan sasaran yang akan dicapai sebagai tujuan dari penerapan teknologi jaringan yang baru. Jaringan serat optik merupakan solusi strategi untuk menggantikan jaringan kabel tembaga sebagai media transmisi.

Pemilihan teknologi serat optik harus memperhatikan beberapa kriteria antara lain: 1). Jenis jaringan dan kapasitas yang akan dipasang, 2). Kemudahan dalam operasi dan pemeliharaan, 3).Konfigursi dan kehandalan sistem yang digunakan, 4). Memiliki kompafibilitas yang tinggi (sesuai standart yang berlaku, 5). Tidak mudah usang dan dijamin produknya, 6). Biaya se efektif mungkin.

Mutu dari pembangunan jaringan serat optik tercermin melalui lamanya umur operasi tersebut. Salah satu faktor yang berkontribusi besar dalam menjaga mutu jaringan serat optik adalah proses penyambungan kabel. Ada dua hal yang harus diperhatikan yaitu: 1). Proses penyambungan (splicing), 2). Proses penutupan alat sambung, dimana tidak boleh bocor atau hampa udara. Contohnya penyambungan serat optik pada jaringan telekomunikasi di Kampus Universitas Negeri Surabaya. Jika penyambungan kabel serat optik bagus maka kestabilan pada operasi transmisi dari jaringan akan lancar dan sebaliknya jika pada penyambungan serat optik jelek maka akan cepat menyebabkaan timbulnya gangguan pada titik sambung, sehingga mengganggu kestabilan transmisi serat optik. Hal ini bisa dilihat dari besarnya rugi-rugi pnyambungan serta redaman cahaya dari serat optik yang disambung. Dikenal dua proses penyambungan fiber optik yaitu : (1).
Penyambungan yang bersifat sementara dengan menggunakan konektor (Conector Terminal Fiber (CTF)), dimana dua serat optik dihubungkan satu dengan lainnya dengan menggunakan konektor sehingga dapat dibongkar pasang sewaktu-waktu, (2). Penyambungan permanen, yaitu penyambungan dirancang untuk penggunaan dalam waktu yang lama. Ada dua model penyambungan permanen, yaitu : secara mekanik dan secara fusi. Cara mekanik adalah proses penyambungan serat optik dengan cara Capillary sílices dan Groove sílices, sedangkan cara fusi adalah proses penyambungan serat optik dengan cara di las atau dilebur dengan menggunakan mesin penyambung (spicing machine).

Tujuan dari penelitian ini adalah mengetahui besarnya spicing loss dan redaman cahaya pada penyambungan serat optik dengan metode fusi.

\section{Penyambungan Serat Optik}

Prosedur penyambungan harus bebas dari kesalahan penjajaran. Rugi-rugi penyambungan yang rendah memerlukan pengolahan kualitas tinggi pada ujung serat, dimana seharusnya halus, rata, dan tegak lurus pada sumbu serat. Secara umum penyambungan di bagi menjadi dua kategori, yaitu: a). Penyambungan permanen, b). Penyambungan nonpermanen. Penyambungan permanen dirancang untuk penggunaan yang lama, sedangkan pada penyambungan nonpermanen biasanya pada konektor sehingga dapat dibongkar pasang sewaktuwaktu. Penyambungan permanen dibagi lagi dalam dua kategori, yaitu: a). Penyambungan fusi, b). Penyambungan mekanik.

\section{Penyambungan Fusi}

Pada teknik ini, dua ujung serat di las bersama-sama pada panjang gelombang 
dielektrik sehingga akan kembali seperti semula. Elektroda akan memancar kemanamana sebagai sumber panas. Skema susunan pada penyambungan serat secara fusi ditunjukkan pada gambar 1 di bawah ini :

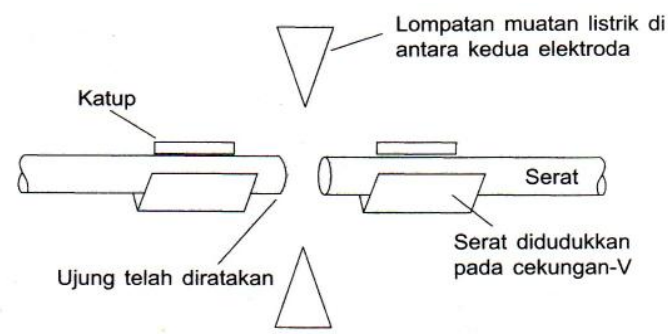

Gambar 1 : Prinsip penyambungan spfusilice. ${ }^{[2]}$

Didalam perangkat splice, serat yang akan disambungkan diletakkan pada sebuah dudukan berbentuk cekungan-V. Serat kemudia dikunci pada kedudukannya oleh sebuah katup magnetik atau mekanis (bekerja berdasarkan gravitasi). Setelah serat terkunci dengan kokoh, serat dan cekungan- $\mathrm{V}$ itu sendiri digerakkan untuk mempertemukan ujung-ujung serat yang hendak disambungkan. Ujung-ujung serat tersebut akan disesuaikan posisinya hingga sempurna. Arus dialirkan dan lompatanlompatan listrik akan timbul diantara kedua elektroda, menimbulkan efek penyoderan pada bagian persambungan serat optik.

\section{Penyambungan Mekanik}

Sebagian besar sambungan splice mekanik memanfaatkan dudukan cekungan-V sebagai landasanya. Sepasang pelat dasar digunakan sebagai landasan ini, dan sebuah cekungan berbentuk huruf $\mathrm{V}$ dibuat tengah masingmasing pelat. Serat optik yang telah dipersiapkan diletakkan didasar cekungan dan kedua ujung yang hendak disambungkan kemudian ditempelkan satu sama lain. Larutan gel

penyelaras indeks bias (index-matcing gel) digunakan dititik persambungan, mengisi celah diantara kedua ujung serat untuk meminimalkan rugi-rugi celah dan efek pemantulan fresnel.

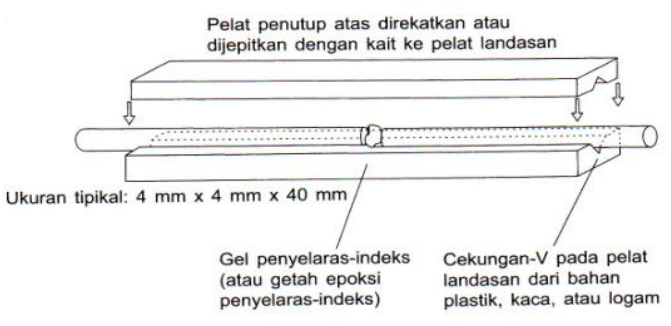

Gambar 2. Prinsip penyambungan splice mekanik.

\section{Metode Penelitian}

Dalam penelitian dapat tiga pekerjaan utama yang dilakukan :

1. Menguapas Lapisan Sekunder, Menyelipkan pembalut splice pada kabel, Membersihkan lapisan primer (silicon) dengan kain katun dan alkohol, Memotong dan meratakan serat,

2. Menyambungan serat optik. Serat optik diletakkan pada cekungan- $\mathrm{V}$ dan digerakkan sehingga kedua ujung bertemu dengan sinar panduan yang dapat dilihat melalui kamera/lensa. Kemudian menjepit keduanya pada posisi itu. Menekan tombol "Start" dan kemudian biarkan proses berjalan dengan sendirinya. Program akan menjalankan seluruh prosedur penyesuaian posisi dan penyambungan, dari awal sampai hingga akhir.

3. Memasang pembalut splice, mengangkat dari kedudukanya dan menggeser pembalut sehingga tepat diatas sambungan. Meletakkan kabel yang telah dibungkus pembalut tersebut diatas oven. Menyalakan oven, setelah proses ini selesai akan mati dengan sendirinya.setelah itu pengukuran dilakukan Pengukuran dilakukan 
dengan menggunakan Cable Analyzer DSP-4000 untuk menentukan loss daya cahaya pada saluaran serat.

\section{HASIL DAN PEMBAHASAN}

Setelah diadakan penelitian terhadap serat optik multimode didapatkan data loss/redaman ( $\mathrm{dB})$ dari Cable Analyzer dan spicing loss (dB) dari Fusion Splicing Machine sehingga bisa diketahui redaman per $\mathrm{Km}$ (kilometer) (dB) nya. .

Tabel 1. Data Redaman Per Km (dB), Loss \& Splicing Loss dari Puskom ke gedung A3 dengan link 0,285 Km.

\begin{tabular}{|c|c|c|c|}
\hline No & $\begin{array}{c}\text { Redaman } \\
\text { Per Km }(\mathrm{dB})\end{array}$ & $\begin{array}{c}\text { Loss/ } \\
\text { Redaman } \\
(\mathrm{dB})\end{array}$ & $\begin{array}{c}\text { Splicing } \\
\text { Loss } \\
(\mathrm{dB})\end{array}$ \\
\hline 1 & 0 & 0 & 0 \\
\hline 2 & 0.0701 & 0,02 & 0 \\
\hline 3 & 0.0350 & 0,01 & 0 \\
\hline 4 & 0 & 0 & 0 \\
\hline 5 & 0 & 0 & 0 \\
\hline 6 & 0 & 0 & 0 \\
\hline \multicolumn{4}{|c|}{ Link / Panjang Kabel 0.285 Km } \\
\hline
\end{tabular}

Tabel 2. Data Redaman Per Km (dB), Loss \& Splicing Loss dari Puskom ke gedung A4 dengan link 0,368 Km.

\begin{tabular}{|c|c|c|c|}
\hline No & $\begin{array}{c}\text { RedamanPer } \\
\mathrm{Km}(\mathrm{dB})\end{array}$ & $\begin{array}{c}\text { Loss/ } \\
\text { Redaman } \\
(\mathrm{dB})\end{array}$ & $\begin{array}{c}\text { Splicing } \\
\text { Loss } \\
(\mathrm{dB})\end{array}$ \\
\hline 1 & 0 & 0 & 0 \\
\hline 2 & 0.0543 & 0,02 & 0 \\
\hline 3 & 0 & 0 & 0 \\
\hline 4 & 0 & 0 & 0 \\
\hline 5 & 0.1630 & 0,06 & 0 \\
\hline 6 & 0 & 0 & 0 \\
\hline \multicolumn{4}{|c}{ Link / Panjang Kabel $0.368 \mathrm{Km}$} \\
\hline
\end{tabular}

Tabel 3. Data Redaman Per Km (dB), Loss \& Splicing Loss dari Puskom ke gedung A6 dengan link 0,347 Km.

\begin{tabular}{|l|l|l|l|}
\hline No & Redaman & Loss/ & Splicing \\
\hline
\end{tabular}

\begin{tabular}{|c|c|c|c|}
\hline & Per Km (dB) & $\begin{array}{c}\text { Redaman } \\
(\mathrm{dB})\end{array}$ & $\begin{array}{c}\text { Loss } \\
(\mathrm{dB})\end{array}$ \\
\hline 1 & 0.0288 & 0,01 & 0 \\
\hline 2 & 0 & 0 & 0 \\
\hline 3 & 0 & 0 & 0 \\
\hline 4 & 0 & 0 & 0 \\
\hline 5 & 0 & 0 & 0 \\
\hline 6 & 0 & 0 & 0 \\
\hline \multicolumn{3}{|c|}{ Link / Panjang Kabel 0.347 Km } \\
\hline
\end{tabular}

Tabel 4. Data Redaman Per Km (dB), Loss \& Splicing Loss dari Puskom ke gedung B1 dengan link 0,26 Km.

\begin{tabular}{|c|c|c|c|}
\hline No & $\begin{array}{c}\text { Redaman } \\
\text { Per Km } \\
(\mathrm{dB})\end{array}$ & $\begin{array}{c}\text { Loss/ } \\
\text { Redaman } \\
(\mathrm{dB})\end{array}$ & $\begin{array}{c}\text { Splicing } \\
\text { Loss } \\
(\mathrm{dB})\end{array}$ \\
\hline 1 & 0 & 0 & 0 \\
\hline 2 & 0.1153 & 0,03 & 0 \\
\hline 3 & 0 & 0 & 0 \\
\hline 4 & 0.0384 & 0,01 & 0 \\
\hline 5 & 0.0384 & 0,01 & 0 \\
\hline 6 & 0.0384 & 0,01 & 0 \\
\hline \multicolumn{4}{|c}{ Link / Panjang Kabel 0.26 Km } \\
\hline
\end{tabular}

Berdasarkan data pada Tabel 1, Tabel 2, Tabel 3, dan Tabel 4 menunjukkan bahwa nilai splicing loss sebesar $0 \mathrm{~dB}$, nilai tersebut menunjukkan bahwa pada penyambungan tidak ada loss sama sekali. Untuk nilai redaman per kilometer/Km nilainya bervariasi, yaitu 0 $\mathrm{dB}, 0.0350 \mathrm{~dB}, 0.0384 \mathrm{~dB}, 0.0543 \mathrm{~dB}$, $0.0701 \mathrm{~dB}, 0.1153 \mathrm{~dB}$, dan $0.1630 \mathrm{~dB}$. Nilai loss atau redaman tersebut diasumsikan ditimbulkan oleh pemasangan konektor antara Cable Analyzer dengan serat optik.

\section{KESIMPULAN}

Dari hasil pembahasan, maka dapat dimpulkan bahwa penyambungan serat optik di Kampus Universitas Negeri Surabaya menghasilkan splicing loss 0 $\mathrm{dB}$ dan memenghasilkan redaman per $\mathrm{Km}$ (kilometer) maksimal $0.1630 \mathrm{~dB}$. Besarnya splicing loss dan redaman per 
Km(kilometer) ini masih bisa digunakan karena masih memenuhi standar yaitu maksimum 0,2 $\mathrm{dB}$ sebagai acuan untuk splicing loss dan maksimum $0,3 \mathrm{~dB}$ sebagai acuan untuk loss(redaman).

\section{DAFTAR PUSTAKA}

1. Crisp, Jhon dan Barry Ellioott. 2006. Serat Optik: sebuah pengantar . Jakarta : Erlangga

2. Frederick, C Allard. 1990. Fiber Optics Hand Book for Enginers and Scientist. United States : Mc Graw Hill.

3. Gerd, Keiser. 1983. Optical Fiber Communications. Mc Graw-hell, international book company 1 .
4. Laud.B. B. 1988. Laser and Optic Nonlinier. Terjemahan. Jakarta : UI Press.

5. Nugraha, Andi Rahman. 2006. Serat Optik. Yogyakarta : CV. Andi Offset.

6. Zanger, Henry and Cynthia. 1991. Fiber Optics Comunication and Other Application. New York : Mac Milan Publishing company Http: //Yulian-Firdaus.Or/Id, Diakses tanggal 31 Agustus 2009

\section{Lampiran I}

Data Losses Fiber Optik di Kampus Universitas Negeri Surabaya

\begin{tabular}{|c|c|c|c|c|c|c|}
\hline No & $\begin{array}{c}\text { Identitas } \\
\text { Kabel }\end{array}$ & $\begin{array}{c}\text { Loss/Redaman } \\
\text { (dB) }\end{array}$ & $\begin{array}{c}\text { Reference } \\
\text { (-dBm) }\end{array}$ & $\begin{array}{c}\text { Panjang } \\
\text { Kabel }(\mathbf{K m})\end{array}$ & $\begin{array}{c}\text { Redaman } \\
\text { Per Km (dB) }\end{array}$ & $\begin{array}{c}\text { Spicing } \\
\text { Loss }(\mathrm{dB}) \\
\end{array}$ \\
\hline 1 & $\begin{array}{c}\text { PUSKOM } \\
\text { TO A3 } 1\end{array}$ & 0 & 31.31 & 0.285 & 0 & 0 \\
\hline 2 & $\begin{array}{c}\text { PUSKOM } \\
\text { TO A3 } 2\end{array}$ & 0.02 & 25.95 & 0.285 & 0.070175439 & 0 \\
\hline 3 & $\begin{array}{c}\text { PUSKOM } \\
\text { TO A3 } 3\end{array}$ & 0.01 & 25.26 & 0.285 & 0.035087719 & 0 \\
\hline 4 & $\begin{array}{c}\text { PUSKOM } \\
\text { TO A3 } 4\end{array}$ & 0 & 25.41 & 0.285 & 0 & 0 \\
\hline 5 & $\begin{array}{c}\text { PUSKOM } \\
\text { TO A3 } 5\end{array}$ & 0 & 25.23 & 0.285 & 0 & 0 \\
\hline 6 & $\begin{array}{c}\text { PUSKOM } \\
\text { TO A3 } 6\end{array}$ & 0 & 25.47 & 0.285 & 0 & 0 \\
\hline 7 & $\begin{array}{c}\text { PUSKOM } \\
\text { TO A4 } 1\end{array}$ & 0 & 24.81 & 0.368 & 0 & 0 \\
\hline 8 & $\begin{array}{c}\text { PUSKOM } \\
\text { TO A4 } 2\end{array}$ & 0.02 & 24.5 & 0.368 & 0.054347826 & 0 \\
\hline 9 & $\begin{array}{c}\text { PUSKOM } \\
\text { TO A4 } 3 \\
\end{array}$ & 0 & 24.79 & 0.368 & 0 & 0 \\
\hline 10 & $\begin{array}{c}\text { PUSKOM } \\
\text { TO A4 } 4\end{array}$ & 0 & 24.6 & 0.368 & 0 & 0 \\
\hline 11 & $\begin{array}{c}\text { PUSKOM } \\
\text { TO A4 } 5\end{array}$ & 0.06 & 30.96 & 0.368 & 0.163043478 & 0 \\
\hline 12 & $\begin{array}{c}\text { PUSKOM } \\
\text { TO A4 } 6\end{array}$ & 0 & 24.89 & 0.368 & 0 & 0 \\
\hline 13 & $\begin{array}{c}\text { PUSKOM } \\
\text { TO A6 } 1\end{array}$ & 0.01 & 24.75 & 0.347 & 0.028818444 & 0 \\
\hline 14 & $\begin{array}{c}\text { PUSKOM } \\
\text { TO A6 } 2\end{array}$ & 0 & 24.47 & 0.347 & 0 & 0 \\
\hline 15 & $\begin{array}{c}\text { PUSKOM } \\
\text { TO A6 } 3\end{array}$ & 0 & 24.75 & 0.347 & 0 & 0 \\
\hline
\end{tabular}




\begin{tabular}{|c|c|c|c|c|c|c|}
16 & $\begin{array}{c}\text { PUSKOM } \\
\text { TO A6 4 }\end{array}$ & 0 & 25.05 & 0.347 & 0 & 0 \\
\hline 17 & $\begin{array}{c}\text { PUSKOM } \\
\text { TO A6 5 }\end{array}$ & 0 & 24.71 & 0.347 & 0 & 0 \\
\hline 18 & $\begin{array}{c}\text { PUSKOM } \\
\text { TO A6 6 }\end{array}$ & 0 & 24.29 & 0.347 & 0 & 0 \\
\hline 19 & $\begin{array}{c}\text { PUSKOM } \\
\text { TO B1 1 }\end{array}$ & 0 & 25.62 & 0.26 & 0 & 0 \\
\hline 20 & $\begin{array}{c}\text { PUSKOM } \\
\text { TO B1 2 }\end{array}$ & 0.03 & 25.85 & 0.26 & 0.115384615 & 0 \\
\hline 21 & $\begin{array}{c}\text { PUSKOM } \\
\text { TO B1 3 }\end{array}$ & 0 & 25.35 & 0.26 & 0 & 0 \\
\hline 22 & $\begin{array}{c}\text { PUSKOM } \\
\text { TO B1 4 }\end{array}$ & 0.01 & 25.18 & 0.26 & 0.038461538 & 0 \\
\hline 23 & $\begin{array}{c}\text { PUSKOM } \\
\text { TO B1 5 }\end{array}$ & 0.01 & 25.73 & 0.26 & 0.038461538 & 0 \\
\hline 24 & $\begin{array}{c}\text { PUSKOM } \\
\text { TO B1 6 }\end{array}$ & 0.01 & 25.92 & 0.26 & 0.038461538 & 0 \\
\hline
\end{tabular}

\section{Lampiran II}
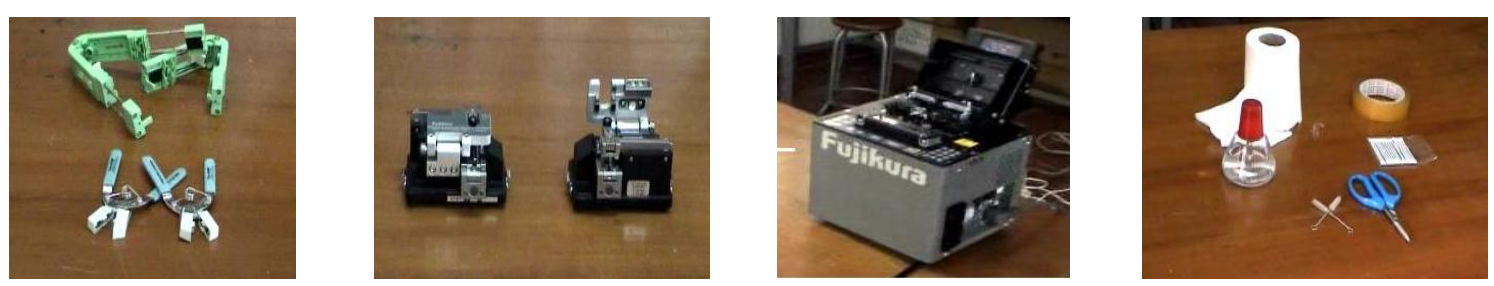

Gambar: Peralatan Khusus Penyambungan Serat Optik
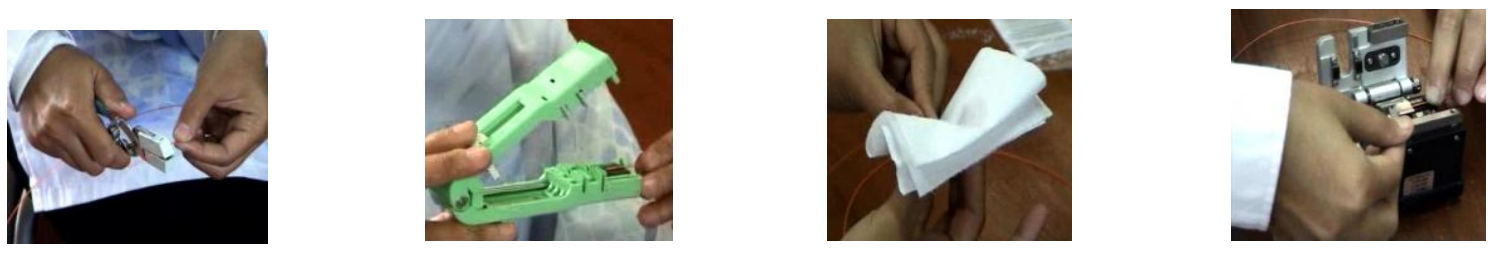

Gambar: Tahap Pemotongan
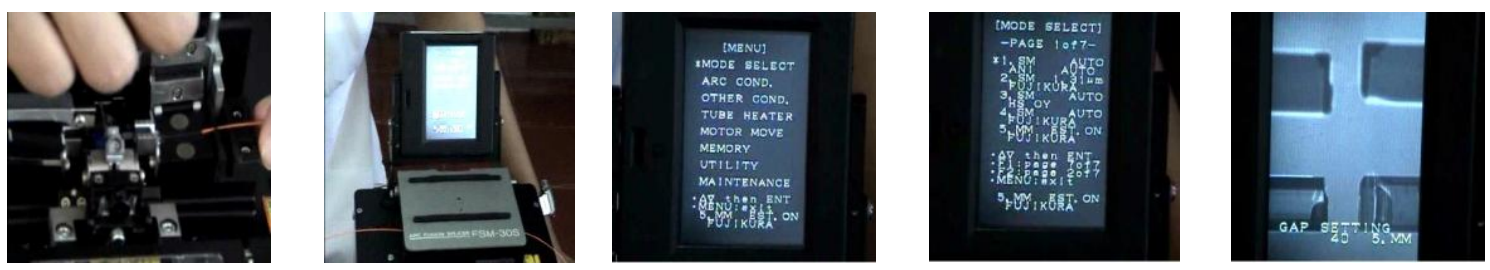

Gambar: Tahap Penyambungan 

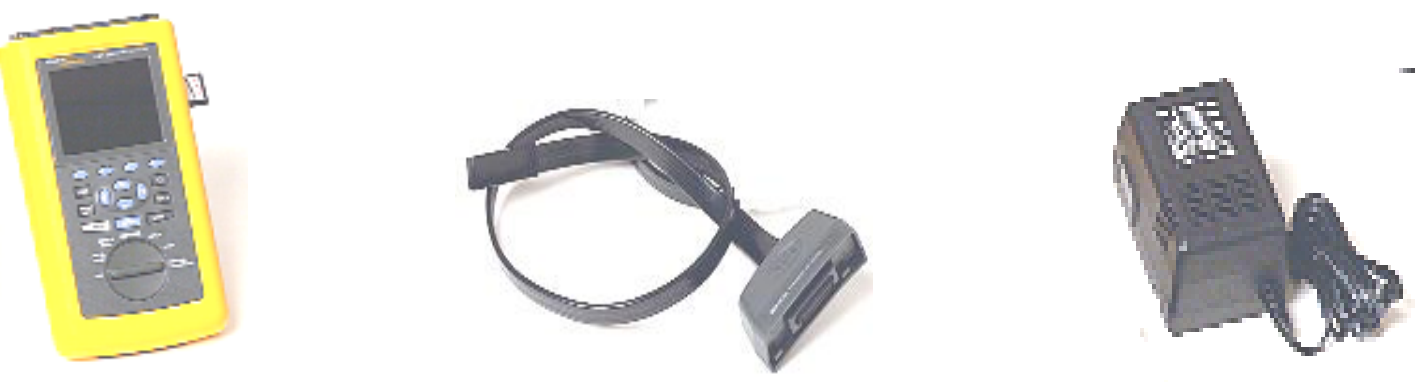

Gambar: Peralatan Cable Analyzer DSP-4000

(http://www.flukenetworks.com) 